\title{
Discovering Collaborative Advantage: The Contributions of Goal Categories and Visual Strategy Mapping
}

By John M. Bryson, Fran Ackermann and Colin Eden

\begin{abstract}
Collaboration can make sense when there is some sort of "collaborative advantage" to be gained, meaning organizations can achieve something together that they cannot easily achieve by themselves. Unfortunately, the literature is essentially silent on how to identify collaborative advantage. This article addresses this shortcoming in the theory of collaborative advantage for public purposes by proposing a set of goal categories that may be used to help articulate collaborative advantage, and the use of visual strategy mapping as part of a facilitated group process to figure out what the collaborative advantage might be. Collaborative advantage as normally understood consists of shared core goals. Collaborative advantage for public purposes should take into account public values beyond shared core goals.
\end{abstract}

\section{Practitioner Points}

- Treat goals as a networked system of aspirations, rather than as a simple hierarchy.

- Consider all of the possible categories of goals: core goals, shared core goals, public value goals beyond shared core goals, negative-avoidance goals, negative public value consequences beyond shared core goals, and not-my-goals.

- Organizations from all sectors may and often do have contributions to make to collaborative advantage for public purposes.

Many scholars have argued that a new approach to public management is emerging that goes beyond traditional public administration and the New Public Management (e.g., Moore, 2013; Denhardt and Denhardt, 2015). The new approach is emerging as a consequence of the importance of public problems facing the world and the realization that governments cannot by themselves effectively address many of these problems. There is also a well-founded worry that public values have been and will be lost as a result of a powerful anti-government rhetoric and a host of market-based and performance-based reforms (Bryson, Crosby and Bloomberg, 2014; Kettl, 2015). While government clearly has a special role to play as a creator of public value and 
guarantor of public values and the public sphere, in a market-based democracy government is not the owner of all the processes and institutions having public value potential or obligations (Peters and Pierre, 1998). Collaboration and cross-sector collaboration have therefore emerged as hallmarks of the new approach in which public managers frequently must work jointly with nonprofit organizations, businesses, the media, and citizens to accomplish public purposes (e.g., O’Leary and Bingham, 2009; Agranoff, 2012; Ansell, 2011; Emerson and Nabatchi, 2015).

Collaboration is a way of achieving together what collaborating organizations cannot achieve separately, and the gain is referred to as "collaborative advantage" (Kanter, 1994). When public organizations are involved, collaborative advantage presumably includes direct or indirect gains in creating public value. Not surprisingly, elected officials, practitioners and scholars frequently tout the benefits of collaboration, which is often required, if not actually mandated, because the presumed benefits - the collaborative advantage - are so obvious. Or perhaps more realistically, there is no other viable option. Indeed, often organizations must "fail into collaboration," having tried to go it alone and not succeeded (Bryson and Crosby, 2008). Unfortunately, while the argument for collaboration may be strong, the empirical literature is quite clear that any form of collaboration is usually difficult and success is hardly assured (Huxham and Vangen, 2005; Thomson and Perry, 2006; Bryson, Crosby, and Stone, 2006, 2015).

At least a part of the problem may be that the collaboration literature is essentially silent on exactly how to discern collaborative advantage other than to engage in dialogue and deliberation, often over extended periods of time (e.g. Gray, 1989; Ostrom, 1990; Huxham and Vangen, 2005; Innes and Booher, 2010). Other literatures offer more in the way of principles and guidance (Eden and Huxham 2001), but still fall short on detailed specifics about the mechanics and fine-grained detail of identifying collaborative advantage. For example, the literatures on interest-based negotiations, conflict management, facilitation, and consensus building literatures provide useful principles and considerable general guidance for getting to win-win solutions in group settings (e.g., Fisher, Ury, and Patton, 2011; Coleman, Deutsch, and Marcus, 2014; Schwarz, 2002; Hunter, 2009; Susskind, McKearnen, and Thomas-Larner, 1999). The deliberative democracy and civic engagement literatures also offer useful general guidance and numerous examples of how groups have found common ground (e.g., Nabatchi, et al., 2012; Nabatchi and Leighninger, 2015). Additionally, the literatures on co-production (e.g., Alford, 
2009; Voorberg, Bekkers, and Tummers, 2014), collective impact (e.g., Kania and Kramer, 2011), evaluation (e.g., Wholey, Hatry, and Newcomer, 2010; Patton 2011), and problem solving (e.g., van Aken, Berends, and van der Bij, 2012) have important insights to contribute. All of these literatures, however, are vague on the specific details of how to come up with collaboratively advantageous solutions.

In this article we offer one possible way of addressing this serious gap in the theory of collaboration. Our research question is: how can potential collaborators be helped to figure out what the collaborative advantage might be for them separately and together in particular circumstances? In response to this question, we present a research and practice-based approach to helping governments and their partners discern collaborative advantage through use of a specific set of goal categories and facilitated strategy mapping. Of these two, we believe the goal categories represent the article's most significant contribution.

We proceed as follows. First, we introduce six goal categories that help advance an understanding of collaboration for public purposes. These include: an organization's core goals, core goals shared by the collaborating organizations, and public value goals beyond core goals and shared core goals. Also included are: negative-avoidance goals, negative public value consequences beyond core goals and shared core goals, and not-my-goals. We also introduce the idea of a goals system, which shows all of these goals as a network (c.f., Eden and Ackermann, 2001). Second, we introduce the process of visual strategy mapping and show how it relates to the goal concepts. The method deliberately seeks to acknowledge the systemic nature of goals systems. Third, we present a brief illustrative case example in which the goal categories and strategy mapping helped identify the collaborative advantage. Fourth, we discuss in more depth issues related to the approach and the case. Finally, we conclude with two tentative propositions meant to guide future research.

We introduce the propositions here, however, to alert the reader to what we see as the significance of this article and to summarize the argument. First, we believe that in comparison with normal dialogue, potential collaborators in a group using the goal categories and visual strategy mapping will have: (1) a clearer, more complete, and systemic understanding of exactly what the potential collaborative advantage is; (2) how they might achieve it and with what risks; and (3) therefore have a better basis for deciding whether to proceed. Second, they will also have 
a better understanding of the potentially broader collaborative advantage that might be achieved by considering public values (benefits and costs broadly conceived) that go above and beyond those for which the collaborators are willing to hold themselves accountable.

\section{Understanding Collaborative Advantage in Terms of Goals}

We argue that collaborative advantage is most easily understood through elaborating theory relating to organizational goals and strategic management. Doing so can help practitioners and researchers better address the challenges posed by collaboration. These challenges include the need to address a public problem where no organization is wholly in charge and where the organizations involved have incompletely overlapping and often conflicting goals (Vangen and Huxham, 2013). For example, as Bozeman (2007, 2) notes, “almost all problems have multiple competing stakeholders seeking to maximize conflicting values," and the values may vary from selfish to altruistic. On the other hand, as Freeman, et al. $(2010,284)$ observe, "not every interaction is a zero-sum game and not every interaction has a win-win solution, but we should do our best to look for the win-win before jumping to other sub-optimal solutions." The challenge is that organizations engaging in collaborations may need help in identifying shared goals that do not negatively affect these organizations' ability to deliver on core organizational goals. Indeed, they may often need help in articulating their own organization-specific goals (Vangen and Huxham, 2012, 2013).

\section{The Goal Categories}

We propose the overarching notion of a goals system and six important categories of goals that are likely to be part of the system (see Table 1). Treating goals as a system means viewing goals as a linked and hierarchically organized network of shared and not-shared goals within and across organizations (Ackermann and Eden, 2011; Vangen and Huxham, 2012). ${ }^{1}$ The work of the collaborators must join in such a way that collaborative advantage can be discerned and realized via collective creation and assignment of meaning, along with the articulation of action responsibilities tied to a subset of the goals system - specifically, the subset that defines collaborative advantage in the situation at hand.

\section{Insert Table 1 About Here (Goal Categories and Collaborative Advantage)}


The first two goal categories will be relatively familiar, while the remaining four may not be. The six categories are: core goals, core goals shared across organizations, and public value goals beyond core goals, negative-avoidance goals, negative public value consequences beyond shared core goals, and not-my-goals. Public value and negative public value consequences are new to the collaboration literature and to the theory of collaborative advantage. Core goals are those goals that are at the core of, or central to, the organization doing what must do to succeed. In other words, if the organization doesn't do reasonably well in achieving these goals it very likely will face serious consequences and indeed may cease to exist (Eden and Ackermann, 2013). For public organizations, many or most of the core goals may be mandated. Shared core goals are core goals that are the same for two or more organizations and cannot easily be achieved except by collaborating. ${ }^{2}$ These are the goals that capture what is ordinarily meant by collaborative advantage (Kanter, 1994; Vangen and Huxham, 2012).

There is a third category of goals that are not core to the collaborating organizations, but do result from the collaborating partners' joint work and also should be considered a part of public value-oriented collaborative advantage. These are public value goals beyond core goals. These are goals, or value achievements, that are valued by the public or enhance the public sphere (Beck Jorgensen and Bozeman, 2007; Benington and Moore, 2011; Bozeman and Johnson, 2014) and go above and beyond core goals without harming the attainment of the collaborators' individual and shared core goals. In economics terms, these may be thought of as positive externalities (Weimer and Vining, 2010), or a bonus above and beyond the accomplishment of core goals. In Moore's (2013) public value accounting scheme, these would be positive consequences of government action that should be added to the benefit side of the ledger. Unfortunately, governments and their partners may well not be willing to be held accountable for these goals, since their achievement is likely to be beyond the control of the separate organizations.

Also, just to be clear, all of the goals of collaborating public organizations, whether shared or not, presumably should be public value goals if these organizations are responsive to their authorizing legislation, applicable mandates, and the broader framework of public governance (Moore, 1995, 2013; Rosenbloom, 2014). In contrast, not all of the goals of collaborating for-profit or non-profit organizations are likely to be public value goals (Bozeman, 2007). 
The concept of a negative-avoidance goal may strike readers as odd, perhaps even oxymoronic. At the extreme, negative-avoidance goals are disaster-avoidance goals (Eden and Ackermann, 2013). The need for recognizing negative-avoidance goals occurs for two reasons. First, it may be necessary to develop strategies to avoid a disaster, i.e., the negative avoidance goal+ (typically called risk-management strategies; see Webster and Stanton, 2015). Second, it may be important to acknowledge the likely and perhaps inevitable negative consequences of doing something to attain positive goals, and therefore important to develop strategies for their avoidance, if possible, or effective management, if inevitable.

The negative-avoidance goal thus has the same general location in a goals system as a goal, but represents an acknowledged negative, or even disastrous, potential outcome to be avoided. In Moore's (2013) public value accounting scheme, the negative consequences of a strategy would show up on the cost side of the ledger. For example, in military operations a natural consequence of pursuing core goals is very often what is referred to as "collateral damage," something military commanders generally acknowledge can happen and will develop strategies to avoid. Explicitly seeking to avoid collateral damage would be a negative-avoidance goal for the organization, if the organization cared about doing so. Otherwise, collateral damage would just be an unintended consequence. The importance of negative-avoidance goals is that often acknowledging their significance for the success of the organization is what drives efforts to collaborate. In other words, these organizations' collaboration strategies are driven in part by trying to avoid these negative outcomes (Bryson and Crosby, 2008). If a specific negativeavoidance goal is shared by the collaborating organizations, then it, too, should be considered part of collaborative advantage.

Negative public value consequences beyond core goals are, as their name implies, recognized undesirable consequences of pursuing a strategy that may accomplish core goals and shared core goals, but epiphenomenally diminishes public value(s) or diminishes the public sphere. These negative goal consequences also should be considered when collaborative advantage is conceived broadly as taking public values, benefits, and costs more fully into account. In economics terms, these may be thought of as negative externalities, or in Moore's (2013) public value accounting scheme, these would also be entered on the cost side of the ledger. 
Finally, not-my-goals are goals claimed by some organization, but not by others. For these other organizations they are "your goals, but not mine." Although these other organizations may nonetheless willingly make a contribution to achieving them, they are not prepared to be held accountable for their attainment. In short, the not-my-goals are those not shared or claimed as part of an organization's or collaboration's goal system. Collaboration typically involves mixed-motive situations for the collaborators - what Vangen and Huxham (2012) call "a tangled web" - in which not all or even most goals are shared. The unshared goals are not-my-goals for the organizations that do not want to be held accountable for their achievement, even though they might actively support their achievement in tangible ways.

A reviewer argued that this category was either unnecessary, or worse, useless, because it could become a catchall for everything the parties will not own and thus is mostly an indicator of a desire to avoid accountability. Our experience, however, is that the category is extremely useful to practitioners. The category helps clarify for the managers and their collaborators what they are willing to contribute toward - a positive public value contribution - but not be held accountable for as they have so little control over it. In other words, the category helps managers orient their strategies for attaining core goals in such a way that they also help attain public value goals that are for them not-my-goals, meaning goals for which they are willing to be held accountable. As will be seen later, important public value goals beyond core and shared core goals can easily fall into this category.

In sum, regardless of sector, collaborative advantage as normally understood consists of shared core goals. A broader public-value focused view of collaborative advantage consists of taking into account shared core goals, public value goals beyond shared core goals, and negative public value consequences of shared core goals (see Table 1). In certain circumstances, negativeavoidance goals and not-my-goals may also be considered part of collaborative advantage. We believe that if the emerging approach to public administration is to fulfil its potential, it should find way of incorporating this broader view of collaborative advantage into its theory and practices.

\section{Unclear Boundaries and Ambiguity in the Goal Categories}

We hasten to acknowledge somewhat unclear boundaries between the six goal categories, especially in practice. For example, there are likely to be significant overlaps in practice between 
not-my-goals, public value goals beyond core goals, and negative public value consequences beyond core goals. Further, a certain amount of goal ambiguity is likely in practice even when the category to which a goal belongs is clear. Chun and Rainey's (2005) define goal ambiguity as the extent to which an organizational goal or set of goals allows leeway for interpretation. We think it makes sense to extend Chun and Rainey's definition beyond organizations to collaborations and beyond core goals to shared core goals and the other goal categories.

The lack of clear goal category boundaries and goal ambiguity are useful prompts in practice for management teams to sort out ownership of, and accountability for, goals. Ambiguity can also be important during the early stages of negotiation, in which some degree of meaning equivocality helps advance conversation (Fisher, Ury and Patton, 2011). The mapping process discussed in the next section uses a causal linking process through which meaning is refined through dialogue and deliberation and the co-creation of a networked goals system comprised of all or most of the goal categories. Meaning is gradually refined as a goal is understood in the context of the adjacent goals in the goals system, whereby a goal's meaning derives from supporting goals and the goals it supports.

\section{Visual Strategy Mapping}

Visual strategy mapping can use the above six goal categories in order to help organizations develop a goals system that clarifies the collaborative advantage to be gained by working together. The strategy elaboration process, however, is only touched upon in this paper due to space limitations.

Visual strategy mapping is an important element of the nascent but growing "visual turn" in organization studies and practice (Bell, Schroeder, and Warren, 2013) that complements, in the case of strategy mapping, the better developed "linguistic turn" in organizational and strategy research (Ford and Ford, 1995; Alvesson and Kärreman, 2000). Visual approaches are being used to develop, for example, theory of change models, logic models, public service business process maps, public and non-profit business models, and, of course, strategy maps.

Visual strategy mapping typically relies on group process facilitation, pragmatic reasoning through dialogue and deliberation (Ansell, 2011), negotiation, and visual representation of statements linked by arrows to show causality and interrelatedness of participants' arguments. The process helps participants "see" what each other is saying, 
understand each other's views, develop a common language, and ideally, through dialogue and deliberation reach common agreement and commitment to mission, goals and strategies. Often the group mapping is computer assisted.

In the case presented this article we used a particular approach to visual strategy mapping developed by Eden and Ackermann (Eden and Ackermann, 1998; Bryson, et al., 2004; Ackermann and Eden, 2011; and Bryson, Ackermann, and Eden, 2014). We used this approach because its developers specifically apply visual strategy mapping in public-sector contexts and because the approach allows potential collaborators to clarify the goals specific to each organization and the collaboration. The approach is therefore especially suited to our purpose.

Visual strategy mapping is a causal mapping process. A causal map is a statements-andarrows diagram. The arrows indicate how one idea or action leads to another in a means-ends relationship. In other words, an arrow means "might cause," "might lead to," "might result in," or some other kind of influence relationship. The term causation is thus used loosely, but is still meant to indicate a plausible understanding about how to change some aspect of the world. Note, however, that a cause-and-effect relationship specifically maps out influence, not chronology. In a visual strategy map the statements represent potential actions that, if taken, are presumed to cause a given outcome(s). Each action in turn is informed by actions that support it as explanations (in-arrows), and each action may be an outcome (out-arrow) of earlier actions. As a result, statements on a map can be both an action (explanation) and an outcome (consequence).

By using a few simple but important rules for formulating statements and creating links, visual strategy mapping makes it possible to articulate a large number of statements and their interconnections in such a way that people can know what to do in an area (issue) of concern, how to do it, and why, since each chain of arrows indicates the causes and consequences of an idea or action. The maps then help focus dialogue and deliberation on which possible statements would or should be chosen and classed as important values, mission, goals, strategies, actions, and underlying assumptions. In other words, the logic structure of a visual strategy map is the same as that of a strategic plan - the difference being that the strategy map details the logic that holds the statements together.

The more deeply individuals engage in developing, wrestling with the meaning of, and revising maps, the more the maps act as a vehicle for negotiating agreements that are owned by 
all in the group. These agreements can become crucial "microfoundations" of agreed goals and ultimately implemented strategy (Barney and Felin, 2013). In relation to discovering collaborative advantage, it is important to emphasize that in practice mapping typically helps groups articulate the collaborative advantages (and disadvantages) that they otherwise would find difficult or even impossible to voice. Depending on the situation, the resulting maps may include anywhere from two dozen to hundreds of statements.

In a facilitated group strategy mapping session, possible issues/actions are solicited from members of the group by having them write down action statements individually on separate self-adhesive cards, one statement per card, or else by having individuals enter their action statements via a wirelessly connected computer network that can project all responses onto a large screen visible to the group. A facilitator helps guide the group as members explore how they believe the statements are causally connected - thus creating a causal map -and ultimately characterized according to various categories (e.g., the goal categories mentioned above, strategies, or actions). New statements are added and older statements may be modified or dropped as the conversation unfolds.

A computerized group support system (GSS) was used in the illustrative case described later. A computer-based group support system can help increase the effectiveness of the process in two ways: First, using a network of tablets connected to a wireless network speeds the production of ideas via parallel processing. Second, participant's responses can be offered anonymously, which means that especially during the early stages of a workshop creativity is more likely. This means that the probability is higher that shared core goals and public value goals beyond core and shared goals (along with the other categories of goals) will surface. ${ }^{3}$ For further discussion of GSSs, see Lewis, 2010.

Visual strategy mapping as a part of strategic management prompts users to view goals and strategy as focused on ways to change an organization and its relationship to other organizations and stakeholders, and often to important parts of its broader environment. For example, goals and strategy might be focused on improving products and services, relationships with key stakeholders, or ways to collaborate with other organizations. Effectively managing strategic change - as opposed to just being lucky - necessarily requires at least a reasonable understanding of causal relationships. Causal mapping therefore becomes a useful strategic 
management tool. As Ackermann and Eden $(2011,10)$ point out more generally, "a causal map graphically presents the basis for action and change."

\section{An Illustrative Case}

We illustrate the approach to establishing collaborative advantage with an example from Europe featuring a for-profit multi-national power generation utility and its public regulator. The case is an illustrative example meant to demonstrate a reasonable claim that the goal categories and visual strategy mapping might help collaborating organizations discern collaborative advantage and advance the common good - though with no guarantees that they will. The case is chosen in part because it fits with the emerging approach to public administration. Specifically, the case shows how public value can be created in areas where it must be co-produced with nongovernmental actors; government has a special role as a guarantor of public values; public management makes an important, but not the only contribution; and democratic and collaborative governance are involved. The cases show what Donahue and Zeckhauser (2011) call "private sector roles for public goals" and Kettl (2015) calls "interweaving public functions and private hands."

The case involves a necessary though informal collaboration between a European country's government regulator and a multi-national power generation utility subject to regular inspections and broader involvements by the regulator with regard to existing plants and development of new plants. Two of the co-authors were involved in the case. They had worked with each organization together and separately over a number of years. Each of the organizations requested their involvement in facilitating a negotiation designed to enable each organization to

achieve its own goals and yet work more constructively with its partner. In short, as Sagawa and Segal $(2000,114)$ say, "In working more closely together, organizations need not, and should not, abandon their central missions." Note that the case is not an example of negotiated rulemaking; instead, it focuses on the creation of a joint goals system.

Over the period of the facilitation support, the organizations' relationship with one another had changed in fundamental ways in keeping with the trust-building cycle identified by Huxham and Vangen (2005): Mutual trust developed, ways of working changed, and most importantly they reached a high level of appreciation that each organization had to meet specific core goals that were often apparently in conflict across the two organizations. As in most 
countries, a regulator must retain absolute independence and so cannot become either a formal collaborator or formal partner, but at the same time the government regulatory agency and the business needed to be able to work together productively as they had no real alternative to being involved with each other. In addition, both organizations recognized that important public values were at stake - that is, the safety of the public and security of the power supply.

We focus on a two-party collaboration for ease of presentation and because of space limitations. The case is hardly representative of the population of all multi-party collaborations, so generalizing from this specific case to other cases is clearly problematic. Nonetheless, in our experience the approach may be extended to larger multi-party collaborations. Doing so will require more workshops and time to help each organization separately develop its own goals system and for the group of organizations to develop a shared goals system. We discuss challenges of using the process for larger collaborations in the conclusions section.

\section{Three Workshops}

The prospect of a massive and hugely expensive project involving major new power generation facilities had emerged. Both organizations believed that it was crucial for them to develop a strategy for effective joint working on the project. They were thus starting with an important link between them - a shared general sense of the problem they needed to solve (Gray, 1989). Each organization decided it would be appropriate to work separately with the co-authors to use visual strategy mapping to develop an organization-specific goals system for the new project. They would then come together to understand how these separate goals systems related to one another and to explore how they might develop a joint goals system that recognized their different and unshared objectives as well as any shared goals. In other words, developing a joint goals system was the starting point for developing strategies to achieve the shared goals. This initial process is the focus of this paper.

The first workshop involved the top management team of the regulator, the second that of the utility, and the third workshop involved both top management teams (the ten most senior people from the regulator and seven from the utility company). Exhibit 1 presents an overview of the process used by these two organizations to figure out the collaborative advantage to be gained from working together.

\section{Insert Exhibit 1 About Here}


The process was initially "strategic issues/risk" driven. When collaborators seek to determine the goals for a project to which they will commit - especially a project of this magnitude - understanding the perceived risks is often of paramount importance because of their actual or potential link to negative-avoidance goals. In practice, however, when a facilitator asks team members for risks, issues also emerge, and when a facilitator asks for issues, risks emerge. While the terms thus are analytically distinct, in practice they are typically treated synonymously. Thus, in order to elicit as wide a range of issues and risks as possible, asking for strategic issues/risks works best. In this case the teams therefore separately identified strategic issues/risks that they believed would significantly affect the future success of their organization and the nascent project without pre-defining what success might be. They then identified and reflected upon the interdependencies between the strategic issues/risks to create an initial visual representation, or map, of the network of issues/risks needing to be addressed. The interdependencies were captured through arrows representing causality - clarifying which issue may lead to another issue.

The next step was exploring the possible consequences of the issues/risks. Issues/risks are only issues/risks if they enable or undermine achieving something valued, and thus "laddering up" from the issues/risks to their consequences allowed for the emergence of goals. Sometimes these were immediate consequences of the issues/risks; in other instances, further issues/risks were surfaced before resulting in a goal. Once the goals had been identified, the same process of considering interdependencies was undertaken. This process enabled the team to create a goals system and, based on that, a first draft of an emergent organizational mission or purpose with regard to the project, which comes from an understanding of the way in which addressing key strategic issues/risks undermines or supports goals.

Beck Jørgensen and Bozeman $(2007,354)$ comment that "if there is any single item for a public values research agenda, it is developing approaches to sorting out values and making sense of their relationships." Usually a system of goals (or values) portrays broadly based and fairly generic goals at the top of a hierarchy (Eden and Ackermann, 2001; Eden and Ackermann, 2013). In businesses these generic goals will be statements such as increase revenue, better control of costs, or increase motivation of all staff. The ultimate top of the hierarchy is likely to be increase profitability, increase profit, or increase shareholder value - goals common to all forprofit organizations. In public organizations the superordinate goal is often a legally mandated 
mission, while in non-profit organizations it similarly may be the mission. These generic goals do not distinguish one organization from another in the same sector. Thus, it is the more specific goals that underpin or help achieve the generic goals that define the purpose of an organization.

Shared core goals that complement each organization's individual goals operationalize collaborative advantage, and facilitate achievement of a win-win outcome beyond what the organizations could achieve themselves (Fisher, 2014). Without a graphical representation of a means-ends network and hierarchy, partners may be unclear about what specific shared core goals the partnership could achieve. Thus a goals system helps clarify what the shared goals are and how they are linked to other core goals. As Beck Jørgensen and Bozeman $(2007,370)$ note, "Neighbor values [adjacent in the means-ends network] are important in two ways. First, identifying neighbor values helps define in greater detail the value used as the starting point. Second, the number of neighbor values provides a clue about the importance of the value...one of the values may have a positive effect on the other." As Keeney $(1988,398)$ also observes, "it is natural to structure a set of objectives, or equivalently, value criteria, into a hierarchy."

Each of the two initial workshops resulted in an organization-specific goals system map consisting of only the goals and their interdependencies. The aim was to ensure that the meaning of any one goal was informed by the other goals that helped achieve it (i.e., that linked into it), as well as the other goals that it helped to achieve (i.e., to which it linked out). During a final review of the map, participants crafted appropriate aspirational wording for the goals.

The third joint workshop occurred within a week of the other workshops to ensure that the content was still fresh in memory. Before the workshop the facilitators engaged in additional preparation. First, they examined the two goals systems to identify possible duplicate goals, which would indicate potentially shared goals across the organizations. Second, they looked for possible ways of linking goals in one system to goals in the other using causal argumentation. The majority of these links emerged during the two individual workshops with a few being introduced by the facilitators based on the conversations held in the individual workshops. Third, these two steps resulted in a draft merged goals system map comprising 39 goals. Twenty-six were utility company goals, eleven were regulator goals, and two were possible shared goals. The merged goals system was the focus of the third workshop, the purpose of which was to see if there was a basis for an effective collaboration. All of the links would be confirmed during the 
third joint workshop. See Figure 1 for the final agreed joint goal system consisting of 22 goals in different categories.

\section{Insert Figure 1 About Here}

\section{Shared Core Goals}

A key potential shared goal that emerged from both organizations' draft goals systems was "ensure that the facility will be safe, reliable, and secure over its entire life." This was not only shared by both organizations, but was also at the center of the draft merged goals system network, indicating further that it was likely to be a shared core goal. This positioning resulted from the goal statement having many other goals supporting it, and it providing support for many others. In particular five goals supported it from the regulator, three goals supported it from utility company, and it supported two regulator goals and nine utility goals.

The goals system in Figure 1 highlights this goal's significance for both organizations. In building a goals system map, those statements (nodes) that are highly linked can be seen as central within the overall network. Moreover, positioning these statements in the center of the map enables a more understandable image as there are fewer links crossing one another. As shown in Figure 1, this shared goal has the greatest number of links (13). As a result of its centrality within the goals system and its importance to both parties (it was the most inter-linked for both organizations), this statement became the obvious starting point for negotiating the final combined agreed goals system. The second shared core goal was related, but had a much shorter time frame: "build a facility that is a world leader" and was not as central (10 links).

Negotiations during the third workshop over the merged goals system led to the recognition that the shared core goals - goals that were core for both organizations - could not easily be achieved without collaborating with the partner. They are thus the most obvious sign of potential collaborative advantage. In other words, they demonstrate Sagawa and Segal's (2000, 108) conclusion that "in both sectors [business and the social sector], partnerships have been a way to expand capabilities beyond what the organization's own resource base permits."

The two teams were surprised to discover that they could achieve more as a result of working together. Instead of simply avoiding a dysfunctional relationship (i.e., avoiding, or at least managing, a negative-avoidance goal), they had managed to create a joint goals system that 
recognized each other's unique core goals and revealed how they could work together to achieve much more via the shared core goals. Needless to say, there were also core goals that belonged only to one of the parties. These include: "profitability" and "creating an export market" for the utility company, and for the regulator, "wider stakeholder confidence in the regulator," "regulator provides timely, proportionate, targeted and balanced regulation, advice and assessment," and "meet political expectations without compromising the regulator mission and values."

The negotiated merging of the two separate goals systems showed complete interlinking, rather than having areas which were predominantly one organization's or the other's. Thus, as can be seen in Figure 1, while some core goals were predominantly one organization's, they had support from goals of the other organization. As far as the participants were concerned, they had expected that there would be two well-separated goals systems with a few links between them. Instead, there were more causal links than anticipated and the presence of these showed interdependence between the regulator and utility company and the clear collaborative advantage to be gained by working together. Thus, even though goals statements that surfaced in each of the separate workshops differed, the links revealed similar meanings in the merged map based on the links in and out of goal statements.

\section{Public Value Goals Beyond Core and Shared Core Goals}

As noted earlier, the combined draft goals system contained 39 goals, including many that were unique to each organization and two potential shared goals. In addition, however, three of the most super-ordinate goals from the utility company's initial workshop appeared to be public value goals; they were not core or shared core goals, but did deliver public value above and beyond the core goals. Importantly they did not undermine core goals. One example was "[have] at the end [of the project] people skilled, proud and keen on doing more, leaving a skills legacy." It is perhaps noteworthy that all of the possible public value goals beyond core goals were developed by the utility company, even though the regulator, as a government agency, might have been expected to readily identify such goals.

As the third workshop progressed, it became clear that the regulator team was comfortable supporting many of the potential public value goals beyond their core goals, regardless of the fact that their having emanated from the utility company. To some extent, these 
goals may have represented taken-for-granted goals on the part of the regulator, and thus not explicitly stated. Alternatively, the fact that the utility brought them up may reflect the greater autonomy a business may enjoy. Yet another alternative is that the regulator, like many public sector organizations, wanted to have its performance measured only against goals that it had a high degree of control over, rather than be criticized for not meeting goals it could only help achieve (Poister, Aristigueta, and Hall, 2014).

Nonetheless, the regulator also realized that there were opportunities for helping achieve general societal goals beyond core goals of either organization and was willing to support their attainment. The energies and competences of collaboration could combine to create something that is of value to all, beyond core goals and shared core goals (Fisher, 2014). The regulator thus clearly accepted "public values are not the exclusive province of government, nor is government the only set of institutions having public value obligations" (Beck Jørgensen and Bozeman, 2007: 374). Significantly, however, neither the government regulator nor the utility agreed to adopt explicitly and publicly these public value goals along with their associated performance indicators because they were not prepared to be held accountable for their achievement. Thus, while the parties were willing to contribute toward achievement of these goals, they were also not-my-goals for each organization as they were not prepared to be held individually responsible for their achievement. The map thus shows an overlap between public value goals and not-mygoals.

\section{Discussion}

The case demonstrates that visual strategy mapping can help users figure out collaborative advantage in a relatively effective way, but only when used as part of an appropriately designed goal- and strategy-setting process. Too often the way senior management teams work together diminishes openness, fosters tentativeness, and discourages exploring creative ways of thinking about what might be achieved (Janis, 1989; Lencioni, 2002). Facilitating the consideration of shared core goals and public value goals is thus difficult. The typical "legitimate" focus of the group is on a debate about core goals, and this discussion is itself problematic. Because each member of a management team has his or her own at least partly unique view of the goals of the organization, any process of negotiation must allow for the surfacing of most if not all of the possible goals as part of negotiating a goals system. Careful 
meeting design, management, and facilitation are thus required to ensure effective idea generation, pragmatic reasoning and dialogue about cause-effect relations, and negotiated agreements on goal systems (Hodgkinson, et al., 2006; Innes and Booher, 2010; Ackermann and Eden, 2011).

An important purpose of this article is to suggest that part of the goal- and strategy-setting process should include explicitly encouraging consideration of all the proposed categories of goals, along with consideration of goals as a system. Otherwise, the role of different goals and their inter-relationships are less likely to be revealed or considered. Introducing the goal categories as possibilities to a group is therefore important. In addition, techniques are needed to bring these concepts to life and show their significance in the world of practice. We believe that visual strategy mapping is an effective technique for doing so, whether computer assisted or not.

We believe the case of the regulator and utility company illustrates the potential merits of the proposed goal categories that go beyond the traditional conception of collaborative advantage. The possible public value goals beyond core goals identified by the utility company were ultimately supported by both organizations, except that for the regulator it was crucially important that they be seen as beyond their core goals and would not interfere with their ability to achieve core goals. Perhaps at least some government organizations find it more difficult than business organizations to acknowledge public value goals beyond core goals (Perri 6, 2005). Moore and Khagrom $(2004,6)$, for example, assert that "government managers typically have much less discretion to define the purposes of their organizations, and the ways they intend to pursue those purposes."

In arguing as we have, we are also acknowledging public values are stakeholder dependent. For example, in the utility-government regulator case, the public value of a skilled labor force would be of value to those who become skilled and to organizations wishing to use these skills, and to the general public in the region where unemployment will drop and the economy benefit. The general public in the country would be less concerned.

\section{Validating the Goals System}

It is all well and good for two or more management teams to reach agreement about a system of goals that includes shared core goals and public value goals beyond core goals, but do they mean it? Will they actually deliver, or are these just words? In other words, do the 
management teams view the goals systems and the agreements they embody as valid prior to implementation of the project. Validity in this case means being reasonable and cogent and having a sound basis in logic. Does the goal system represent a sound basis for the leadership work of providing direction, alignment, and commitment (Drath, et al., 2008)?

A number of ways are available for testing the possibility that the agreements are not just simply espoused goals that will not be implemented. These indicators include: (1) the results of strategic risk assessment, (2) the meanings revealed by the statements and associated causal links, and (3) the nature of the performance indicators developed by the group tied both to the core shared goals and public value goals beyond shared goals.

Strategic Risk Assessment. An agreement on the goals system is a fundamental aspect of agreeing on strategy. When developing a strategy for a project of this magnitude, performing a risk assessment is typically the primary basis for negotiating strategies that will mitigate the key risks (and avoid negative-avoidance goals). For this reason the second part of each of the two initial workshops was devoted to eliciting risks that would compromise the attainment of the goals. The process used was similar to that for developing the goals system, where participants identified risks and causally linked them. Gradually a causal map developed that showed how risks were related, as opposed to the group developing a traditional risk register where risks are listed and their interactions ignored.

If the agreed goals are meaningful then the strategic risks are most likely to be identified with regard to the most important goals, and especially with the negative-avoidance goals (cf. Webster and Stanton, 2015). A process of risk assessment in relation to achieving the goals therefore tends to surface and link real worries about delivering on the goals that a team is most keen to achieve.

Risks of two kinds were identified during the initial workshops: (1) the risks that the other organizations would create, and (2) the risks created by their own organization. In the case of the utility and the regulator, the highest combination of risk impact and probability of occurrence were: "program delivery pressures (affect quality and safety)," "lack of control of construction activities," and "personal relationships break down as increased program pressure builds." For both organizations these were risks that could undermine what later became the central collaborative goal of "ensure that facility will be safe, reliable $\&$ secure over its entire life 
to meet our context in a fit-for-purpose way" and other goals directly related to specific organizational goals that serve immediate stakeholders.

Thus, notwithstanding the participants' wish to achieve wider public value goals, the risk focus was unsurprisingly on short-term, organization-specific goals. The participants' real energy was focused on the core goals of each organization rather than on goals beyond core goals. This encourages us to believe that the processes of negotiation and the outcome of the goal-setting reflected both a cognitive and emotional commitment for the participants to the goals system, but particularly to their own core goals, as might be expected. The public value goals were seen as good to achieve, but clearly "above and beyond" core goals.

Vague Platitudes or Goals That Will Be Implemented? Relatedly, how do we know that shared core and public value goals beyond core goals will be goals-in-action rather than the typically very broad and vague goals that are agreeable to all parties, but unlikely to be very meaningful or implemented (Vangen and Huxham, 2012)? The strategic risk assessment and negotiated strategies for mitigation provided one check, in that the key strategies were identified and then causally linked to the agreed goals to demonstrate the goals-in-action. In this sense, ambiguous values/goals became less ambiguous when their means-ends context is clear (Beck Jørgensen and Bozeman, 2007, 357). In other words, instrumental goal ambiguity was reduced (see Rainey and Jung, 2015). Thus, the development of goals statements in the context of meansends relationships adds more realism than simply pronouncing nice sounding aspirations without a meaningful context. In the utility company and regulator case, the creation of a network of goals gave an action-oriented meaning to each of the goals and placed them in a meaningful network of goals (also reducing priority ambiguity; see Rainey and Jung 2015).

Additionally, the facilitators' experience with both teams in both a group and one-on-one individual settings meant they knew something of the meanings of non-verbal behaviors. The facilitators were thus able to gain a sense that the parties to the negotiation were sincere and the behaviors in the group setting mirrored behaviors and attitudes in other settings. As further evidence, the computer support system enabled anonymous expressions of commitment, as well as veto of potential agreements.

The Impact of Performance Indicators. Often the creation of, and agreement to, performance indicators attached to each goal will clarify the operational meaning of the goal, 
even when the indicators are qualitative (reducing evaluative ambiguity; Rainey and Jung, 2015). The recognition of the tension created between the expectations of others and self-determination usually provides some insight into commitment levels. Worryingly, any central government's emphasis on more quantifiable performance indicators and on austerity may drive down the overall effectiveness of the public sector in situations where collaboration is mandated or desirable (Perri 6, 2002).

In the utility company-government regulator case, the regulator team was particularly keen to have its performance measured against goals that they felt they had a high degree of control over, meaning their core goals and shared core goals. This circumstance suggests that different types of performance indicators are required for evaluating public value goals beyond core goals. Eden and Ackermann (1998, 262), Provan and Milward (2001), and Innes and Booher (2010) discuss cases in which "tracking indicators" were, or can be, used to encompass different ways of measuring performance that go beyond core goals. Thus, while the collaborators agreed to the public value goals and see value in being able to measure their attainment, they do not take sole responsibility for it, as their attainment is too dependent on the work of others. They therefore just committed to "tracking" performance in relation to these goals, not to being held accountable for it.

\section{Conclusions}

We have presented an approach to figuring out multi-organizational collaborative advantage through the use of a specific set of goal-related categories and visual strategy mapping in facilitated group strategy-making sessions. The main contributions of this article to the collaboration literature - and specifically to the theory of collaborative advantage - are to offer potentially relevant goal categories and an explicit, operational way for collaborators to discover collaborative advantage.

The approach may be particularly advantageous for achieving greater integration of public and private activities to develop a set of shared common goals associated with creating public value that neither government, non-profit, nor business organizations could achieve on their own. Increasingly institutions beyond governments are recognizing they have public value obligations (Beck Jørgensen and Bozeman, 2007, 374), as acknowledged in the corporate social responsibility literature for decades (Crane and McWilliams, 2009) and also by the US federal 
government's Government Performance and Results Modernization Act and its associated performance management system (Moynihan, 2013), along with similar state and local government systems (Bryson, 2011). The collective impact movement (Kania and Kramer, 2011) also recognizes this and we believe the proposed goal categories and visual strategy mapping could help further government performance management, corporate social responsibility, and collective impact goals. Indeed, the approach to creating a joint goals system also can be used to inform and strengthen a range of important processes, including alternative dispute resolution processes, negotiated rule-making methods, policy negotiations, and so forth, since each might be helped by clarifying joint goals systems (e.g., Bingham, O’Leary, and Nabatachi, 2005).

The article helps highlight the possibility that a single-minded focus by public organizations on meeting their core goals alone can significantly diminish their potential for creating public value (c.f. Rosenbloom, 2014; Bryson, Crosby and Bloomberg, 2014). The continual increase in scrutiny, emphasis on more quantifiable performance indicators, and pressure for austerity can drive down the overall effectiveness of government organizations by potentially making it harder to achieve shared core goals and public value goals beyond core goals (Perri 6, 2002; Patton, 2011). Interestingly, the utility-regulator case raises the possibility that in some circumstances it may be easier for a business to go above and beyond core goals than for a government organization, in that the utility contributed most of the public value goals beyond core goals to the collaborative endeavor.

Our hope is that the proposed goal categories and visual strategy mapping might help alleviate some of the challenges of identifying means and ends for achieving core, shared core, and public value goals beyond core goals in situations of collaboration, networked governance, and a "hollow state" (Milward and Provan, 2000, 2006). Put differently, we argue that the emerging approach to public administration should incorporate this more expansive, public value-regarding view of collaborative advantage into its theory and practices if it is to fulfill its potential.

We used a two-party case to illustrate the approach, because presenting a more complicated multi-party case would have taken too much space. We think the approach clearly is applicable, however, to larger multi-party collaborations. More collaborators would mean additional workshops to allow each organization to clarify its own goals system. In our 
experience, most organizations do not understand their goals fully or as a goals system.

Achieving this understanding first, before developing a goals system for the collaboration is important. More collaborators would also mean more workshop time for the whole group in order to determine the collaboration's goals system. Facilitators would also need more time in order to prepare a draft goals system for the collaborators to consider.

Even if the proposed goal categories and approach are presumed to have some merit, scholars are still likely to have a number of concerns. First, there is a need for greater conceptual clarity around the meaning of the goal categories and legitimate overlaps among them. Indeed, regardless of their utility for practitioners, some might argue that the categories of public value goals beyond core goals, negative public value consequences beyond core goals, negativeavoidance goals, and not-my-goals are not legitimate goal categories; instead the idea of goals should be limited to what we are calling core goals and perhaps shared core goals.

Second, scholars may question the reasoning behind the placement of arrows and their directionality. In response, we would say that the point is not whether the arrows placed by management teams can withstand scholarly scrutiny. The point is whether the conversation leading to the arrows was useful for the teams themselves in developing a reasonable and defensible way forward. Evaluating whether the resulting goals and strategies work during implementation is a different question.

Third, scholars may reasonably assert that the goals in the maps are too ambiguous to be useful. We do not dispute that there is a certain degree of goal ambiguity in the maps. We would argue, however, that a certain amount of goal ambiguity at the beginning of a mapping session can be quite helpful, and that the use of the goal categories and the strategy mapping process can make an important contribution toward reducing directional, evaluative, and priority goal ambiguity to desirable levels for the management teams involved (Rainey and Jung, 2015, 8384).

We also assert that the categories and process can help operationalize the concept of goal validity called for by Rainey and Jung $(2015,90$, emphasis in original). We have made use of four ways of validating goals prior to implementation, including: 1) the fact that senior management teams developed and agreed to the goals systems; 2) the results of strategic risk assessment exercises; 3 ) the meanings revealed by the means-ends network statements and 
causal links; and 4) the nature of the performance indicators developed by the group. An additional important method of validation beyond the scope of this study is whether the goals embedded in the maps actually lead to useful strategies in practice, including learning about the appropriateness of the goals. In other words, scholars should take account of both ex ante and ex post goal validity.

To conclude, we have introduced an approach to figuring out cross-organizational and cross-sector collaborative advantage. The approach makes use of visual strategy mapping in a facilitated group strategy making session and six categories of goals within a goals system. Collaborative advantage can be of two different types. The first is the conventional view, which defines collaborative advantage as shared core goals. The second is more expansive and more broadly public value oriented. The broader approach includes shared core goals and public value goals beyond core goals, while simultaneously taking into account negative public value consequences beyond core goals, and in certain circumstances negative-avoidance goals and notmy-goals (depending on the specific goal). Collaborative advantage as indicated by shared core goals is thus a subset of the more expansive conception of collaborative advantage that takes a broader view of public value into account.

We summarize our argument via a set of tentative propositions that double as hypotheses we believe merit further research:

Proposition 1. In comparison with normal dialogue, potential collaborators using visual strategy mapping as part of a facilitated group strategy mapping session will have (1) a clearer, more complete, and systemic understanding of exactly what the potential collaborative advantage is, as that term is ordinarily understood; (2) how they might achieve it and with what risks; and (3) therefore have a better basis for deciding whether to proceed.

Propositions 2. Potential collaborators using visual strategy mapping as part of a facilitated group strategy mapping session will have (1) a clearer understanding of the potential collaborative advantage that goes beyond core goals and shared core goals to create greater public value; (2) how they might achieve it and with what risks; and (3) therefore have a better basis for deciding whether to proceed.

Testing these propositions poses a number of challenges for research. To fully test them a variety of methodologies will need to be used, including: action research, comparative case 
studies, natural experiments, and laboratory experiments. If the propositions are supported by further research, they outline an important way to improve collaboration, collaborative governance, and the creation of public value. Given the large and increasing importance of collaboration, and the clear evidence that it is hardly an easy answer to hard problems, anything that might make achievement of collaborative advantage easier is worth pursuing.

\section{Endnotes}

${ }^{1}$ Our approach therefore is normative in contrast to Vangen and Huxham's (2012) research aim of uncovering via grounded theory a set of dimensions with which to compare and contrast collaboration goals. The goal dimensions that emerged from their research are: level, origin, authenticity, relevance, content, and overtness.

${ }^{2}$ Core goals and shared core goals are thus "mission-intrinsic," and not the same as what Rosenbloom (2014) calls "mission-extrinsic public values." These latter values are typically not central to achievement of a public organization's core mission. Instead, they usually relate to mandated general processes by which the organization is to pursue its mission; e.g., legal requirements affecting administrative procedures, transparency, due process, public notification and comment, and so forth. Performance measures may be tied to these mission-extrinsic values, but they would not be measuring performance directly related to the core mission.

${ }^{3}$ The visual mapping approach employed a software package called Decision Explorer that enables the data captured to be viewed according to the needs of the group. Thus it is possible to focus solely on issues/risks, goals, or any other category (www.banxia.com). The group support system (GSS) that was used is called Group Explorer. Group Explorer is a portable computer network system that allows participants to contribute their thoughts (statements and linking of statements) via a laptop computer and for their statements to be displayed as a network on a publicly viewable screen. The system does not discourage normal conversation, but rather allows time slots in which higher productivity, greater procedural justice (Tyler and Blader, 2003), anonymity, and experimentation are possible. The visualization or picture (network of statements) produced by the group can be continuously edited as conversation refines the material and agreements are reached. Group Explorer uses Decision Explorer to display and analyze material. For more information, contact co-author Colin Eden. 


\section{References}

Ackermann, Fran and Colin Eden, 2011. Making Strategy: Mapping Out Strategic Success. London: Sage.

Agranoff, Robert, 2012. Collaborating to Manage. Washington, DC : Georgetown University Press.

Alford, John, 2009. Engaging Public Sector Clients: From Service-Delivery to Co-Production. Basingstoke: Palgrave Macmillan.

Alvesson, Mats and Dan Kдrreman. 2000. "Taking the Linguistic Turn in Organizational Research." Journal of Applied Behavioural Science 36:136-158.

Ansell, Christopher, 2011. Pragmatist Democracy: Evolutionary Learning as Public Philosophy. New York: Oxford University Press.

Barney, Jay and Teppo Felin. 2013. "What Are Microfoundations?" Academy of Management Perspectives 27:138-155.

Beck Jorgensen, Torben B. and Barry Bozeman. 2007. "Public Values: an inventory." Administration \& Society 39:

Bell, Emma, Samantha Warren, Jonathan Schroeder, and eds., 2013. The Routledge Companion to Visual Organization. New York: Routledge.

Benington, John. and Mark H. Moore. 2011. "Public Value in Complex and Changing Times." In Public Value: Theory and Practice, edited by John Benington and Mark Moore, 1-120. Basingstoke: Palgrave Macmillan.

Bozeman, Barry, 2007. Public Values and Public Interest. Washington, DC: Georgetown University Press.

Bozeman, Barry and Japera Johnson. 2014. "The Political Economy of Public Values: A Case for the Public Sphere and Progressive Opportunity." The American Review of Public Administration doi: $10.1177 / 0275074014532826$ :

Bryson, John M., 2011. Strategic Planning for Public and Nonprofit Organizations (4th Edition). San Francisco: Jossey-Bass.

Bryson, John M., Fran Ackermann, and Colin Eden, 2014. Visual Strategy. San Francisco: Wiley.

Bryson, John M., Fran Ackermann, Colin Eden, and Charles Finn, 2004. Visible Thinking: Unlocking Causal Mapping for Practical Business Results. Chichester: Wiley.

Bryson, John M. and Barbara C. Crosby. 2008. "Failing into Cross-sector Collaboration Successfully." In Big Ideas in Collaborative Public Management, edited by Lisa. B. Bingham 
and Rosemary O'Leary, 55-75. Armonk,NY: M. E. Sharpe.

Bryson, John M., Barbara C. Crosby, and Laura Bloomberg. 2014. "Public value governance: Moving beyond traditional public administration and New Public Management." Public Administration Review 74:445-456.

Bryson, John M., Barbara C. Crosby, and Melissa M. Stone. 2015. "Designing and Implementing Cross-Sector Collaborations: Needed and Challenging." Public Administration Review 75:647663.

Bryson, John M., Barbara C. Crosby, and Melissa M. Stone. 2006. "The Design and Implementation of Cross-Sector Collaborations: Propositions from the Literature." Public Administration Review $66: 44-55$.

Chun, Young H. and Hal Rainey. 2005. "Goal Ambiguity in US Federal Agencies." Journal of Public Administration Research and Theory 15:1-30.

Coleman, Peter T., Morton Deutsch, and Eric C. Marcus, 2014. The Theory of Conflict Resolution: Theory and Practice, Third Edition. San Francisco: Jossey-Bass.

Crane, Andrew and Abigail McWilliams, 2009. The Oxford Handbook of Corporate Social Responsibility. New York: Oxford University Press.

Denhardt, Janet. V. and Robert. B. Denhardt, 2015. The New Public Service: Serving, Not Steering. Fourth Edition. Armonk, NY: M. E. Sharpe.

Donahue, John D. and Richard J. Zeckhauser, 2011. Collaborative Governance: Private Sector Roles for Public Goals in Turbulent Times. Princeton and Oxford: Princeton University Press.

Eden, Colin and Fran Ackermann, 1998. Making Strategy: The Journey of Strategic Management. London: Sage.

Eden, Colin and Fran Ackermann. 2001. "A Mapping Framework for Strategy Making ." In Mapping Strategy, edited by A. Huff and M. Jenkins, 173-195. London: Wiley.

Eden, Colin and Chris Huxham. 2001. "The Negotiation of Purpose in Multi-Organizational Collaborative Groups." Journal of Management Studies 38:351-369.

Eden, Colin and Fran Ackermann. 2013. "Problem structuring: on the nature of, and reaching agreement about, goals." EURO Journal of Decision Processes 1:7-28.

Emerson, Kirk and Tina Nabatchi, 2015. Collaborative Governance Regimes. Washington, DC: Georgetown University Press.

Fisher, Roger, William L. Ury, and Bruce Patton, 2011. Getting to Yes: Negotiating Agreement Without Giving In, Revised Edition. New York: Peguin.

Fisher, Thomas. 2014. "Public Value and the Integrative Mind: How Multiple Sectors Can 
Collaborate in City Building." Public Administration Review 74:457-464.

Ford, J. D. and L. W. Ford. 1995. "The Role of Conversations in Producing Intentional Change in Organizations." Academy of Management Review 20:541-570.

Freeman, R. E., Jeffrey S. Harrison, Andrew C. Wicks, Bidhan L. Parmar, and Simone De Colle, 2010. Stakeholder Theory: The State of the Art. Cambridge: Cambridge University Press.

Gray, Barbara, 1989. Collaborating: Finding Common Ground for Multiparty Problems. San Francisco: Jossey-Bass.

Hodgkinson, Gerard P., Richard Whittington, Gerry Johnson, and Mirela Schwarz. 2006. "The role of strategy workshops in strategy development processes: formality, communication, coordination and inclusion." Long Range Planning 39:479-496.

Hunter, Dale, 2009. The Art of Facilitation (Revised Edition). San Francisco: Jossey-Bass.

Huxham, Chris and Siv Vangen, 2005. Managing to Collaborate. London: Routledge.

Innes, Judith and David Booher, 2010. Planning with Complexity: An Introduction to Collaborative Rationality for Public Policy. New York: Routledge.

Janis, Irving L., 1989. Crucial Decisions. New York: Free Press.

Kania, John and Mark Kramer. 2011. "Collective Impact." Stanford Social Innovation Review Winter Issue:36-41.

Kanter, Rosabeth M. 1994. "Collaborative Advantage:The Art of Alliances." Harvard Business Review July:

Keeney, Ralph. 1988. "Structuring Objectives for Problems of Public Interest." Operations Research 36:396-405.

Kettl, Donald F. 2015 . "The Job of Government: Interweaving Public Functions and Private Hands." Public Administration Review DOI: 10.1111/puar.12336:

Lencioni, Patrick M., 2002. The Five Dysfunctions of a Team. San Francisco: Jossey-Bass.

Lewis, L. Floyd. 2010. "Group Support Systems: overview and guided tour." In Handbook of Group Decision and Negotiation, edited by D. M. Kilgour and Colin Eden, 249-268. Dordrecht: Springer.

Milward, H. Brinton and Keith G. Provan. 2000. "Governing the Hollow State." Journal of Public Administration Research and Theory 10:359-379.

Milward, H. Brinton and Keith G. Provan, 2006. A Manager's Guide to Choosing and Using Collaborative Networks. Washington, DC: IBM Center for the Business of Government.

Moore, Mark, 1995. Creating Public Value: Strategic Management in Government. Cambridge, 
MA: Harvard University Press.

Moore, Mark H., 2013. Recognizing Public Value. Cambridge, MA: Harvard University Press.

Moore, Mark H. and Sanjeev Khagram, 2004. On Creating Public Value: What Business Might Learn from Government about Strategic Management, Corporate Social Responsibility Initiative Working Paper No 3. Cambridge, MA: John F Kennedy School of Government Harvard University.

Moynihan, Donald, 2013. The New Federal Performance System: Implementing the GPRA Modernization Act. Washington, DC: IBM Center for the Business of Government.

Nabatchi, Tina, G. J. Gastil, Michael Weiksner, and Matt Leighninger, 2012. Democracy in Motion. New York: Oxford University Press.

Nabatchi, Tina and Matt Leighninger, 2015. Public Participation for $21^{\text {st }}$ Century Democracy. San Francisco: Jossey-Bass.

Ostrom, Elinor, 1990. Governing the Commons. Cambridge, UK: Cambridge University Press.

O’Leary, Rosemary, Lisa Blomgren Bingham, and eds., 2009. The Collaborative Public

Manager. Washington, DC: Georgetown University Press.

Patton, Michael Q., 2011. Developmental Evaluation. New York: The Guilford Press.

Perri 6. 2002. "Joined-Up Government in the West beyond Britain: A Provisional Assessment." In Joined-Up Government., edited by Vernon Bogdaner, 43-106. New York: Oxford University Press.

Peters, B. Guy and John Pierre. 1998. "Government without Governance? Rethinking Public Administration." Journal of Public Administration Resaerch and Theory 8:223-243.

Poister, Theodore H., Maria P. Aristigueta, and Jeremy L. Hall, 2014. Managing and Measuring Performance in Public and Nonprofit Organizations: An Integrated Approach. San Francisco: Jossey-Bass.

Provan, Keith G. and H. B. Milward. 2001. "Do Networks Really Work? A Framework for Evaluating Public Sector Organizational Networks." Public Administration Review 61:414-423.

Rainey, Hal G. and Su J. Chan. 2015. "A Conceptual Framework for Analysis of Goal Ambiguity in Public Organizations." Journal of Public Administration Research and Theory 25:71-99.

Rosenbloom, David H. 2014. "Attending to Mission-Extrinsic Public Values PerformanceOriented Administrative Management: A View from the United States." In Public

Administration and the Modern State: Assessing Trends and Impact. edited by Eberhard Bohne, John D. Graham, and Jesse Paul Lehrke, Hampshire, UK: Palgrave Macmillan. 
Sagawa, Shirley and Eli Segal. 2000. "Common Interest, Common Good: Creating Value Through Business and Social Sector Partnerships." California Management Review 42:105-122.

Schwarz, Roger M., 2002. The Skilled Facilitator: A Comprehensive Resource for Consultants, Facilitators, Managers, Trainers and Coaches. San Francisco: Jossey-Bass.

Susskind, Lawrence, Sarah McKearnan, and Jennifer Thomas-Larmer, 1999. The consensus building handbook: A comprehensive guide to reaching agreement. Thousand Oaks, CA: Sage.

Thomson, Anne-Marie and James L. Perry. 2006. "Collaboration Processes: Inside the Black Box." Public Administration Review 66 (Supplement):19-32.

Tyler, Tom R. and Steven L. Blader. 2003. "The Group Engagement Model: Procedural Justice, Social Identity, and Cooperative Behavior ." Personality \& Social Psychology Review 7:349361.

van Aken, Joan, Hans Berends, and Hans van der Bij, 2012. Problem Solving in Organizations: A Methodological Handbook for Business and Management. Cambridge, UK: Cambridge University Press.

Vangen, Siv and Huxham Chris. 2012. "The Tangled Web: Unraveling the Principle of Common Goals in Collaborations." Journal of Public Administration Research and Theory 22:731-760.

Vangen, Siv and Chris Huxham. 2013. "Building and Using the Theory of Collaborative Advantage." In Network Theory in the Public Sector: Building New Theoretical Frameworks, edited by Robyn. Keast, Myrna P. Mandell, and Robert Agranoff, New York: Taylor and Francis.

Voorberg, William H., Bekkers V. J. J. M., and Lars G. Tummers. 2014. "A Systematic Review of Co-Creation and Co-Production: Embarking on the Social Innovation Journey." Public Management Review 17:1333-1357.

Webster, D. W. and T. H. Stanton, 2015. Improving Government Decision Making through Enterprise Risk Management. Washington, DC: IBM Center for the Business of Government.

Weimer, D. and A. Vining, 2004. Policy Analysis: Concepts and Practice (Fourth Edition). Englewood Cliffs, NJ: Prentice-Hall.

Wholey, Joseph. S., Harry. P. Hatry, and Kathryn. E. Newcomer, 2010. Handbook of Practical Program Evaluation, Third Edition. San Francisco: Jossey-Bass. 
Table 1: Goal Categories and Collaborative Advantage

\begin{tabular}{|c|c|c|c|c|}
\hline Goal Type/Category & Description & $\begin{array}{l}\text { Illustration from Utility-Regulator } \\
\text { Case }\end{array}$ & $\begin{array}{l}\text { Shaded Area } \\
\text { Represents } \\
\text { Collaborative } \\
\text { Advantage as } \\
\text { Commonly } \\
\text { Understood }\end{array}$ & $\begin{array}{l}\text { Shaded Area } \\
\text { Represents the } \\
\text { Broader Public } \\
\text { Value-Focused } \\
\text { Approach to } \\
\text { Collaborative } \\
\text { Advantage }\end{array}$ \\
\hline Core goals (primary) & $\begin{array}{l}\text { Goals that are at the core of, or } \\
\text { central to an organization } \\
\text { achieving its mandate } \\
\text { [note: for a private organization } \\
\text { these are goals that are expected } \\
\text { to realize profit or shareholder } \\
\text { value] }\end{array}$ & $\begin{array}{l}\text { For the regulator: "develop greater } \\
\text { public confidence in the regulator" } \\
\text { For the utility: "have profitable utility" }\end{array}$ & & \\
\hline Shared core goals & $\begin{array}{l}\text { Core goals shared by more than } \\
\text { one organization made possible } \\
\text { through collaboration }\end{array}$ & $\begin{array}{l}\text { "ensure that the facilities will be safe, } \\
\text { reliable, and secure over its entire life to } \\
\text { meet our context in a fit for purpose } \\
\text { way" }\end{array}$ & & \\
\hline $\begin{array}{l}\text { Public value goals } \\
\text { beyond core goals }\end{array}$ & $\begin{array}{l}\text { Goals valued by the public which } \\
\text { extend benefits beyond any } \\
\text { organization's core goals and } \\
\text { shared core goals and which no } \\
\text { organization is willing to be held }\end{array}$ & $\begin{array}{l}\text { "at the end, members of the public, } \\
\text { skilled, proud and keen on doing more, } \\
\text { leaving a skills legacy: provide a social } \\
\text { benefit to the community" }\end{array}$ & & \\
\hline
\end{tabular}




\begin{tabular}{|c|c|c|c|}
\hline & accountable for & & \\
\hline $\begin{array}{l}\text { Negative-avoidance } \\
\text { goals }\end{array}$ & $\begin{array}{l}\text { Goals which are likely or possible } \\
\text { negative consequences of } \\
\text { strategies to achieve other goals, } \\
\text { and thus are risks that need to be } \\
\text { assessed and possibly managed }\end{array}$ & $\begin{array}{l}\text { Hypothetical negative-avoidance goal } \\
\text { not on map: "NOT overzealous shut- } \\
\text { downs" } \\
\text { [note: this is likely to be a significant } \\
\text { worry for the utility company and so } \\
\text { something to be avoided at all costs] }\end{array}$ & $\begin{array}{l}\text { Depending on } \\
\text { the specific } \\
\text { negative- } \\
\text { avoidance goal }\end{array}$ \\
\hline $\begin{array}{l}\text { Negative public value } \\
\text { consequences beyond } \\
\text { core goals }\end{array}$ & $\begin{array}{l}\text { Undesirable public value } \\
\text { consequences generated by } \\
\text { pursing strategies to achieve core } \\
\text { goals and shared core goals. } \\
\text { While they strategies may } \\
\text { achieve core goals and shared } \\
\text { core goals, they also yield } \\
\text { negative public consequences. }\end{array}$ & $\begin{array}{l}\text { "NOT 'the lights go out"' } \\
\text { [Note: the statement arose as 'the lights } \\
\text { go out' is a phrase used in the power } \\
\text { generation industry for the long term } \\
\text { loss of enough power to keep the lights } \\
\text { on. The 'NOT' was inserted by the } \\
\text { group to recognize that the goal was to } \\
\text { avoid this outcome] }\end{array}$ & \\
\hline Not-my-goals & $\begin{array}{l}\text { In collaborations these are goals } \\
\text { of other organizations which } \\
\text { those not owning them are not } \\
\text { prepared to be held accountable } \\
\text { for }\end{array}$ & $\begin{array}{l}\text { "All stakeholders (inc the public) retain } \\
\text { confidence in the regulatory process } \\
\text { across all industries } \\
\text { [Note: the regulator aimed to contribute } \\
\text { to this goal but did not wish to be held } \\
\text { accountable for their contribution, } \\
\text { because they did not wish be held } \\
\text { accountable for ALL stakeholders, } \\
\text { across ALL industries] }\end{array}$ & $\begin{array}{l}\text { Depending on } \\
\text { the specific not- } \\
\text { my-goal }\end{array}$ \\
\hline
\end{tabular}


Exhibit 1. A Workshop Process for Discovering Collaborative Advantage

Overarching purpose: Establish a joint goals system that identifies where working together can create outcomes that could not be achieved otherwise, while also acknowledging each organization's goals and how they interact with the goals of the other organization(s).

\section{Set-Up (for additional details see Bryson, Ackermann, and Eden, 2014)}

- Gain agreement with the two organizational lead persons regarding the two-stage workshop design (as noted below)

- Identify an appropriate room

- Select participants

- Agree on a timescale - ideally no more than a week between each workshop

\section{Stage One: Separate workshops for each organizational team.}

Purpose: Develop an agreed-upon draft goals system that spells out 'What we want' (goals) and how the goals relate to each other.

General Introduction to workshop

Why use a computer-assisted group support system (GSS)? A GSS:

- Provides all participants with wirelessly connected consoles that allow:

o everyone to speak simultaneously

$\circ$ anonymity and therefore more openness

- Supports groups in creating maps that reflect causality (means-ends and risk systemicity)

- Enables easy and continuous editing of maps to reflect provides organisational memory subsequent to the workshop

- enables hard copy production as and when required for each reference

\section{Activity}

1. Review 'rules of engagement.' (for example, mobile phones on silent)

2. Ask participants to use their consoles to capture individually:

- What issues/risks they fear the other organization(s) might create

- What issues/risks they think their own organization might create

3. Begin to explore the links between the issues/risks using the material captured and roughly clustered into themes,. Doing so will aid development of a map that shows the interconnections beween issues and risks posed to one's own organization, the other organization(s), and the two organizations jointly.

4. Explore the structure of the map identifying where there seem to be heavily linked clusters (potential themes) of material. Check the links' accuracy and comprehensiveness.

5. Identify key risks (those risks which have many links into and out of them) and then use a Delphi technique to agree on impact and probability with respect to those risks.

6. In the light of the risk map, and taking into account the priorities revealed through the Delphi activity, begin to identify the underlying goals as they are revealed through questioning what goals/objectives are threatened by the risks. 


\section{Conclusion}

Review the goals system and provide brief description re next steps

Repeat with other organisation(s).

\section{Off-line work:}

1. Facilitators merge the two sets of material into a new model keeping a copy of the originals.

2. Facilitators identify overlapping goals, cross-links between goals, and possible goal categories indicating shared goals in order to develop a single combined goals system map

3. Facilitators identify emerging risk clusters/themes worth addressing with both groups

4. Facilitators gain agreement from each organisation about what is to be declared from their own workshop

\section{Stage Two: Joint workshop to establish a shared goals system that clarifies the collaborative advantage of working together}

Purpose: Agree on the shared goals for the collaboration and how they relate to each other. Develop a draft goals system that recognizes the core goals of each organization and yet identifies shared goals, and especially those goals that could not be attained without collaboration. As part of the process, recognize goals that seek to avoid possible serious disasters, and goals that could benefit the wider community without hurting each organization's core goals

\section{Introduction}

- Review of previous introduction, including use of the GSS and rules of engagement

- Explain what has been done 'off-line'

\section{Activity}

1. Explore and discuss emergent joint risk themes and identify possible joint risk mitigation strategies

2. Explore and discuss emergent joint goals system created from initial workshops and offline work making sure to attend to negative-avoidance goals and public value goals beyond shared goals

3. Agree on a joint goals system and draft risk mitigation strategies and their role in attaining goals

Conclusion Agree on a one page summary statement and provide participants with hard copy. 


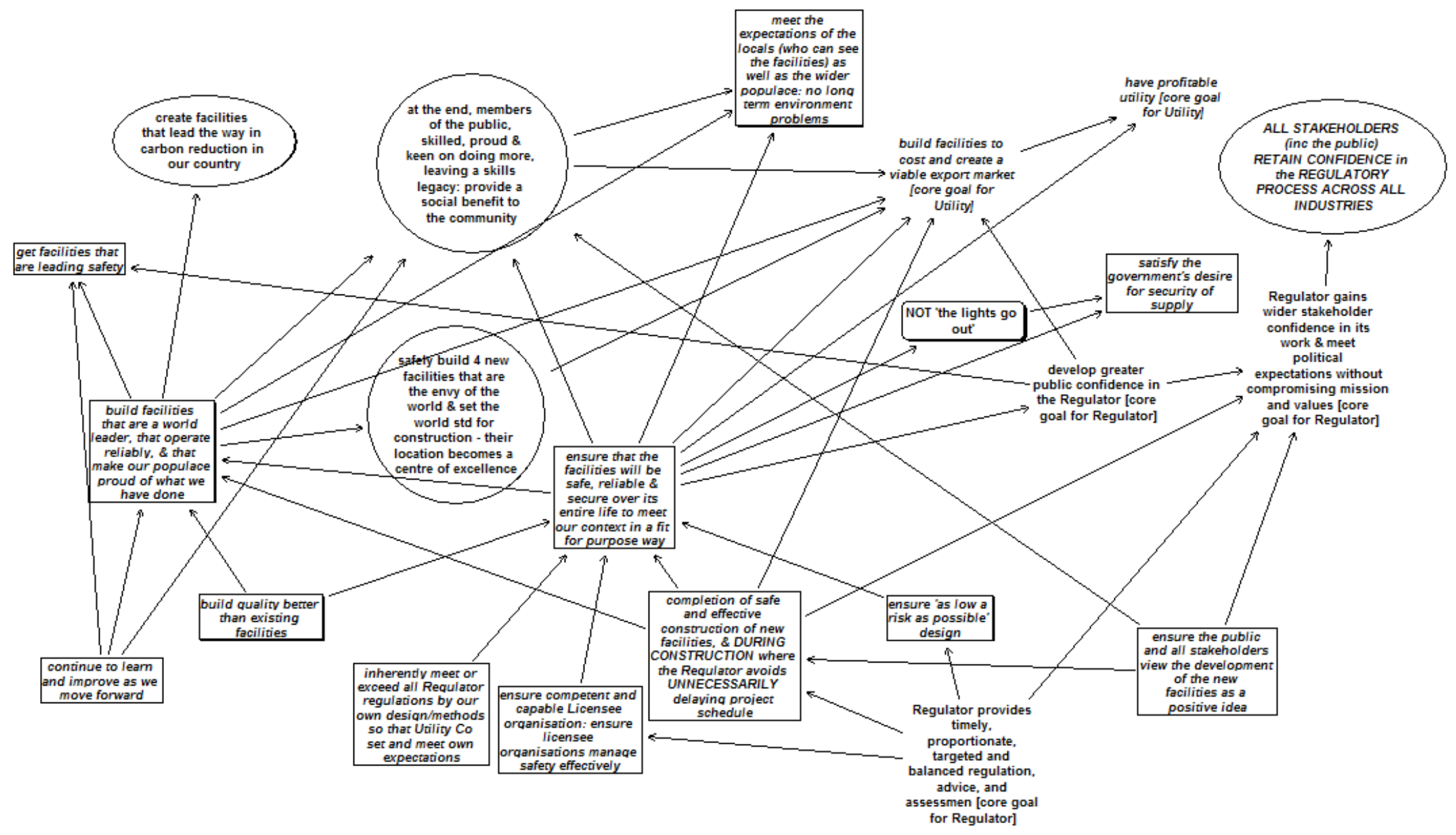

Figure 1: The Final Agreed Goals System Map. LEGEND: 5 unique core goals shown with no box; 1 negative public value goals beyond core goals shown as a rounded rectangle; 12 shared core goals shown as squared rectangles; 4 public value goals beyond core goals shown as ovals; and 1 not-my-goal shown as an oval with CAPITALIZED text 